\title{
Effect of Metallurgical Factors of Low Carbon Steel Sheets on Stress Corrosion Cracking in Methanol Solution*
}

\author{
By Kameo MATSUKURA ${ }^{* *}$ and Kazuaki SATO**
}

\begin{abstract}
Synopsis
Studies were carried out on the effects of chemical composition, manufacturing condition and heat-treatment of low-carbon rimmed hot-rolled steel sheets on its susceptibility to stress corrosion cracking in $60^{\circ} \mathrm{C}$ reagent methanol containing $0.01 w t \%$ formic acid and $0.1 w t \%$ water by using a constant strain-rate test.

Similar studies were done for various cold-rolled steel sheets and pure iron sheets,

Carbon content $(0.001 \sim 0.12 w 0 \%)$ did not affect the susceptibility. Chromium additions $(0.04 w \mathrm{w} \%$ and over) increased the resistance to cracking, whereas temper rolling and lower coiling temperature of hot-rolled sheets decreased the resistance. Also a higher cooling rate of the steel sheet from the austenite region and low temperature heat treatments $\left(100^{\circ} \sim\right.$ $300^{\circ} \mathrm{C} \times 5 \mathrm{hr}$ ) increased the SCC susceptibility.

The effect of the strain rate on the SCC susceptibility of a bent or straight form specimen in the methanol solution was investigated. It was found that both specimens showed SCC at the strain rate $\dot{\varepsilon}=10^{-4} \sim 10^{-5} \mathrm{sec}^{-1}$ and the cracking depth observed in the bent specimen ( $\max .0 .28 \mathrm{~mm}$ ) was greater than that in the straight specimen ( $\max .0 .05 \mathrm{~mm}$ ).

The same SCC as that in the methanol solution was observed in reagent ethanol $\left(\mathrm{C}_{2} \mathrm{H}_{5} \mathrm{OH}\right)$, methyl cellosolve $\left(\mathrm{H}_{3} \mathrm{COC}_{2} \mathrm{H}_{4} \mathrm{OH}\right)$, and ethylene glycol $\left(\mathrm{C}_{2} \mathrm{H}_{4}(\mathrm{OH})_{2}\right)$ containing formic or acetic acid and water.
\end{abstract}

\section{Introduction}

It was previously reported ${ }^{1)}$ that stress corrosion cracking (SCG) was observed in mild steel in methanol solution containing small quantities of formic acid*** ( $\mathrm{HCOOH}, 0.005 \sim 0.02 \mathrm{wt} \%$ ) and water*** $\left(0.05 \sim 0.2 \mathrm{wt}^{\%} \%\right)$. The observation was led by the experience of finding a leakage through a crack in the beaded portion of a drum (whose inside was phosphate treated by zinc phosphate or ferric phosphate type) filled with methanol solution of vinyl resin. Appropriate steps for reducing SCC on drums were; 1) to prevent any contact between the solution and steel by completely coating the inside of the drums, 2 ) to prevent temperature rise, and 3) to reduce tensile stress in the drum beads by changing the storage method from nesting ( $\max .24 \mathrm{~kg} / \mathrm{mm}^{2}$ in three-tier arrangement) to standing on end, and so forth. On the other hand, the SCG susceptibility of the lowcarbon steel sheets, out of which drums are made, could be reduced by the use of different manufacturing conditions. In fact, it was ascertained that the cracking rate of the drums differed with each lot of steel material. Thus, the SCG susceptibility of pure iron and various types of hot-rolled and cold-rolled steel sheets in methanol solution were investigated and then the effects of hot-rolled sheet manufacturing conditions (strip coiling temperature, temper rolling reduction and heat-treatment conditions) on the SCC susceptibility of steel sheets for the drums were studied.

It was also reported ${ }^{1)}$ previously that the $W$-type specimen (under constant stress) and the bent specimen (under constant strain-rate) reproduced $\mathrm{SCC}$ in the SCC test of mild steel in methanol solution of vinyl resin, while common type specimens, i.e., $U$-type specimen and as-rolled straight specimen (straight specimen) did not exhibit the reproducibility. In the SCC test of mild steel in aqueous solution of nitric acid and aqueous solution of caustic alkali, the straight specimens under constant load or under constant strain-rate generated SCC, hence, bent specimens $^{2)}$ have been seldom tested. Therefore, the effect of bending on SCG in methanol solution was studied for mild steel specimen.

Cracking was also observed on low-carbon steel sheet drums filled with methyl cellosolve (ethylene glycol monomethyl ether). As SCG was thought to occur on the drums filled with organic solvents other than methanol, SCC tests of low carbon steel sheet were carried out in methyl cellosolve, ethanol and ethylene glycol.

\section{Test Method}

The constant strain-rate test method was chosen for the SCG test described in the previous report.1) Rectangular specimens were dipped into methanol solution kept at a constant temperature and stretched at a constant speed of $0.05 \mathrm{~mm} / \mathrm{min}$ using an Instron type (tensile) tester. The time to failure of the specimen was chosen as an indicator of the SCC susceptibility.

The test solution was prepared by adding 0.005 to $0.03 \mathrm{wt} \%$ formic acid, the amounts required to generate $\mathrm{SCC}$ in mild steel, as a corrosive agent and $0.1 \mathrm{wt} \%$ water as an SCG accelerator, to pure-grade reagent methanol. If added in excess, however, water became an SCC inhibitor. The test temperature of methanol solution was $60^{\circ} \pm 0.1^{\circ} \mathrm{C}$. The $\mathrm{pH}$ value measured with a $\mathrm{pH}$ meter was 6.2 for puregrade reagent methanol and 3.3 for that of the methanol solution containing $0.1 \%$ water and $0.01 \%$ formic acid.

Specimens were taken from levelled hot or cold strip sheets after being paid out of a coil and cut parallel $(L)$ or crosswise $(C)$ to the rolling direction

* Originally published in Tetsu-to-Hagané, 63 (1977), 1016, in Japanese. English version received October 11, 1977.

** Sakai Works, Nippon Steel Corp., Chikkō-Yawatamachi, Sakai 590.

*** Formic acid and water are produced through formaldehyde (HCHO) by oxidation of methanol. 
to a size of $12 \mathrm{~mm} W \times 500 \mathrm{~mm}$. Parallel sections of $10 \mathrm{~mm} W \times 400 \mathrm{~mm} L$ (called "long gauge-length specimen ") and $10 \mathrm{~mm} W \times 60 \mathrm{~mm} L$ ("short gaugelength specimen") were provided by machining (Fig. 1). Specimens were bent to a $10 \mathrm{~mm}$ radius in a bend tester because straight specimens would not lead to SCC in the methanol solution. ${ }^{1)}$ The hot and cold strips used for the specimens of 1.2 or $2.0 \mathrm{~mm}$ thickness were commercially produced. The hotrolled sheets were pickled for scale removal in a $15 \% \mathrm{HCl}$ solution $\left(70^{\circ} \mathrm{C}\right)$ and neutralized and then dried. Some specimens were surface-finished using chemical polishing liquid (100 cc of hydrogen peroxide $\mathrm{H}_{2} \mathrm{O}_{2}$ and $15 \mathrm{cc}$ of hydrofluoric acid $\mathrm{HF}$ and water) and tested to see if there would be any difference in SCG susceptibility from that of pickled sheets. No difference was noticed.

The pure iron sheets were prepared as a laboratory product by putting electrolytic iron through the processes of vacuum melting, casting, hot rolling (to $6 \mathrm{~mm}$ thickness), cold rolling (to $1.2 \mathrm{~mm}$ thickness) and vacuum annealing at $700^{\circ} \mathrm{C}$ for $5 \mathrm{hr}$. The chemical composition and mechanical properties of these specimens are shown in Table 1.

\section{Test Results and Discussions}

\section{Effects of the Properties of Steel Sheets on SCC Suscep-} tibility

\section{SCC Susceptibility of Hot-rolled Sheets}

Four kinds of hot-rolled low-carbon rimmed steel sheets produced commercially under similar conditions (steels No. A to D, $1.2 \mathrm{~mm}$ thickness) were tested to examine the difference of the SCG susceptibility among them and the dependence on test conditions. Figure 2 shows the test results of long gauge-length specimens immersed in a methanol solution of 0.005 to $0.03 \mathrm{wt} \%$ formic acid. Under the weak SCG condition of $0.005 \mathrm{wt} \%$ formic acid addition, specimen D was broken after $12.8 \mathrm{hr}$ by the SCC initially generated inside the bend and the other after $14.6 \mathrm{hr}$, whereas specimens $\mathrm{A}$ to $\mathrm{C}$ were not broken even after $20 \mathrm{hr}$, but a slight SCG was noticed inside the surface of each bend. Under a comparatively severe $\mathrm{SCC}$ condition of $0.01 \mathrm{wt} \%$ formic acid addition, spec-

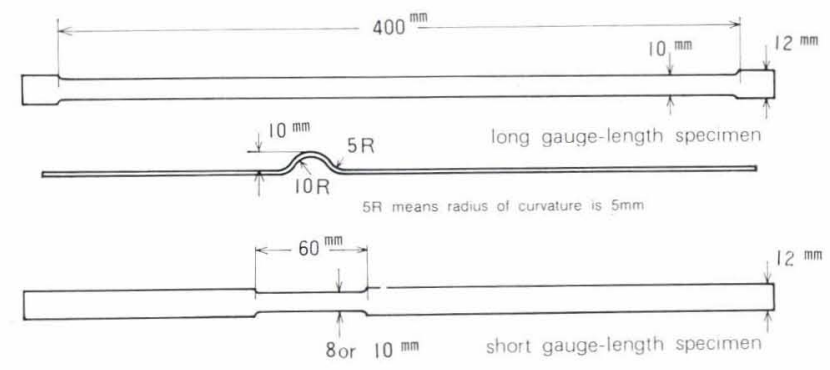

Fig. 1. Specimen used for constant strain rate test

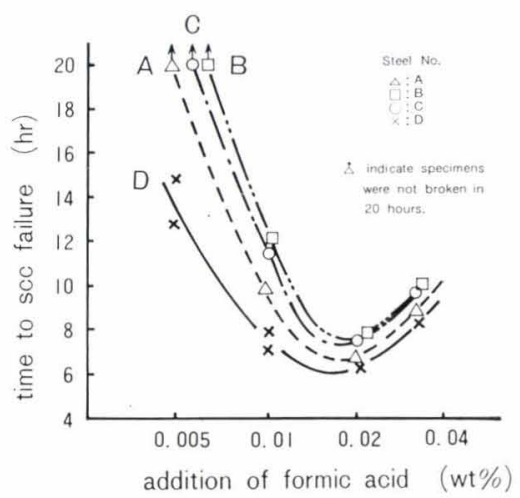

Fig. 2. SCC susceptibility of hot-rolled sheets A to D (long gauge-length specimen, formic acid and $0.1 \%$ water added to reagent methanol, test temp.: $60^{\circ} \mathrm{C}$ )

Table 1. Chemical composition and mechanical properties of sheets used

\begin{tabular}{|c|c|c|c|c|c|c|c|c|c|c|c|c|c|c|c|c|c|c|}
\hline & \multirow{2}{*}{$\underset{\mathrm{kg} / \mathrm{mm}^{2}}{T S}$} & \multirow{2}{*}{$\begin{array}{l}\text { steel } \\
\text { No. }\end{array}$} & \multicolumn{12}{|c|}{ chemical composition (wt \%) } & \multicolumn{4}{|c|}{ mechanical properties (L) } \\
\hline & & & C & Si & $\mathrm{Mn}$ & $P$ & $\mathrm{~S}$ & $\mathrm{Cu}$ & $N$ & 0 & Sol Al & $\mathrm{Cr}$ & V & $\mathrm{Nb}$ & $\mathrm{YPkg} / \mathrm{m}^{2}$ & $T S \mathrm{~kg} / \mathrm{mm}^{2}$ & $\mathrm{El} \%$ & $\mathrm{HRB}$ \\
\hline \multirow{6}{*}{$\begin{array}{l}\text { hot } \\
\text { rolled } \\
\text { sheet }\end{array}$} & \multirow{3}{*}{30} & A & 0.06 & 0.01 & 0.35 & 0.014 & 0.016 & 0.01 & 0.002 & 0.043 & 0.004 & 0.01 & & & 24.0 & 34.5 & 43 & 50 \\
\hline & & B & 6 & I & 33 & 22 & 25 & 1 & 1 & 34 & 3 & 1 & & & 23.4 & 34.9 & 40 & 50 \\
\hline & & C & 8 & 1 & 36 & 26 & 32 & 1 & 1 & 37 & 3 & 1 & & & 24.7 & 36.7 & 43 & 55 \\
\hline & \multirow{5}{*}{ class } & $\mathrm{D}$ & 11 & 1 & 48 & 15 & 16 & 1 & 1 & 21 & 4 & 1 & & & 27.4 & 40.2 & 39 & 60 \\
\hline & & 0 & 0.04 & 0.01 & 30 & 17 & 18 & 1 & 1 & 30 & 1 & 1 & & & 23.2 & 34.6 & 45 & 51 \\
\hline & & $\mathrm{P}$ & 5 & 1 & 34 & 8 & 8 & 1 & 1 & 10 & 2 & 1 & & & 24.2 & 34.8 & 40 & 52 \\
\hline \multirow{2}{*}{ (Cr add.) } & & E & 5 & 1 & 35 & 14 & 15 & 1 & 1 & 35 & 1 & 0.036 & & & 24.6 & 32.4 & 46 & 49 \\
\hline & & $\mathrm{F}$ & 6 & 1 & 37 & 16 & 18 & 1 & 1 & 25 & 2 & 0.104 & & & 25.6 & 35.8 & 42 & 50 \\
\hline \multirow{5}{*}{$\begin{array}{l}\text { cold } \\
\text { rolled } \\
\text { sheet }\end{array}$} & \multirow{2}{*}{$\begin{array}{c}30 \\
\text { class }\end{array}$} & G & 5 & 1 & 24 & 15 & 19 & 1 & 2 & 41 & 2 & 0.03 & $\mathrm{Tr}$ & $\mathrm{Tr}$ & 23.9 & 33.2 & 46 & 48 \\
\hline & & $\mathrm{H}$ & 5 & 1 & 33 & 12 & 18 & 4 & 7 & 5 & 36 & 1 & $\mathrm{Tr}$ & $\mathrm{Tr}$ & 15.9 & 31.7 & 47 & 38 \\
\hline & \multirow{3}{*}{$\begin{array}{c}50 \\
\text { class }\end{array}$} & 1 & 9 & 1.36 & 1.55 & 22 & 5 & 2 & 5 & 3 & 25 & 0.19 & 0.011 & $\mathrm{Tr}$ & 40.6 & 58.5 & 29 & 79 \\
\hline & & $\mathrm{J}$ & 12 & 1.37 & 1.53 & 12 & 5 & 2 & 6 & 3 & 13 & 0.01 & $\operatorname{Tr}$ & 0.032 & 39.6 & 59.9 & 29 & 78 \\
\hline & & $K$ & 11 & 0.29 & 1.28 & 11 & 5 & 1 & 8 & 3 & 28 & 1 & 0.051 & 30 & 42.0 & 53.6 & 28 & 78 \\
\hline \multirow{3}{*}{$\begin{array}{l}\text { pure iron } \\
\text { cold rolled } \\
\text { sheet }\end{array}$} & \multirow{3}{*}{$\begin{array}{c}20 \\
\text { class }\end{array}$} & $\mathrm{L}$ & 0.001 & 0.001 & $\mathrm{Tr}$ & 3 & 5 & $\mathrm{Tr}$ & 2 & 8 & 7 & $\mathrm{Tr}$ & $\mathrm{Tr}$ & $\mathrm{Tr}$ & 12.3 & 23.4 & 56 & \\
\hline & & $M$ & 2 & 1 & $\mathrm{Tr}$ & 4 & 7 & $\mathrm{Tr}$ & 1 & 5 & 7 & $\mathrm{Tr}$ & $\mathrm{Tr}$ & $\mathrm{Tr}$ & 15.9 & 25.9 & 59 & 14 \\
\hline & & $N$ & 4 & 1 & $\mathrm{Tr}$ & 3 & 5 & $\mathrm{Tr}$ & 1 & 17 & 7 & $\mathrm{Tr}$ & $\mathrm{Tr}$ & $\mathrm{Tr}$ & 13.6 & 23.3 & & 20 \\
\hline
\end{tabular}

Other tramp elements of pure iron sheet: $\mathrm{Ni}: 0.011$, As : 0.007, Sn: 0.005, Mo: Trace

Sheet thickness : $1.2 \mathrm{~mm}(\mathrm{~A} \sim \mathrm{N}, \mathrm{P}), 2.0 \mathrm{~mm}(\mathrm{O})$

Grain size (ASTM No.) : 8.5 9.5 (A F, O, P), $7 \sim 8(\mathrm{G}, \mathrm{H}), 10 \sim 11.5(\mathrm{I} \sim \mathrm{K}), 5 \sim 6(\mathrm{~L} \sim \mathrm{N})$ 
imen D was broken after about $8 \mathrm{hr}$, A after $10 \mathrm{hr}$, and $\mathrm{B}$ and $\mathrm{C}$ after 11 to $12 \mathrm{hr}$. When the addition of formic acid was increased to $0.02 \mathrm{wt} \%$, the time to failure was shortened and the difference among specimens $\mathrm{A}$ to $\mathrm{D}$ were reduced. Yet, the order did not change from that of $B \sim C>A>D$.

Specimen D is most susceptible to SCC, specimens $\mathrm{B}$ and $\mathrm{C}$ are least and specimen $\mathrm{A}$ is intermediate. These results show that a $0.01 \mathrm{wt} \%$ addition of formic acid was considered to be appropriate as a test condition for ascertaining differences in SCG susceptibility among these specimens. No correlations, however, were recognized between the order of SCG susceptibility, chemical composition and mechanical properties of the four specimens. The SCC susceptibilities of the specimens were indicated by the time to failure, as stated previously, but this could have been affected by the ductility and toughness of the specimens. No correlation, however, was found between the total elongation (ductility) of specimens $\mathrm{A}$ to $\mathrm{D}$ and the time to failure. Hence it was concluded that the time to failure could be a primary indicator of the SCC susceptibility. The differences in the SCG susceptibility among the specimens can be attributed, as will be explained later in this report, to heat-treating conditions including cooling rate after hot rolling and coiling temperature, and to rolling conditions such as temper rolling and leveling.

Then short gauge-length specimens were tested under the same test conditions as those described above. Generally, time to failure was shorter than that of the long gauge-length specimens, but the order of the SCG susceptibility of the four kinds of specimens was in general agreement with that of the latter. It was concluded, therefore, that the long gaugelength specimens are suited to the SCC susceptibility tests of various materials having only slight differences in the SCC susceptibility, while the short gaugelength specimens are suitable to test materials with large differences in the SCC susceptibility in a relatively short time.

\section{SGC Susceptibility of Cold-rolled Steel Sheets and Pure Iron Sheets}

Cold-rolled steel sheets are used to make drums as are hot-rolled sheets. Figure 3 shows the comparison

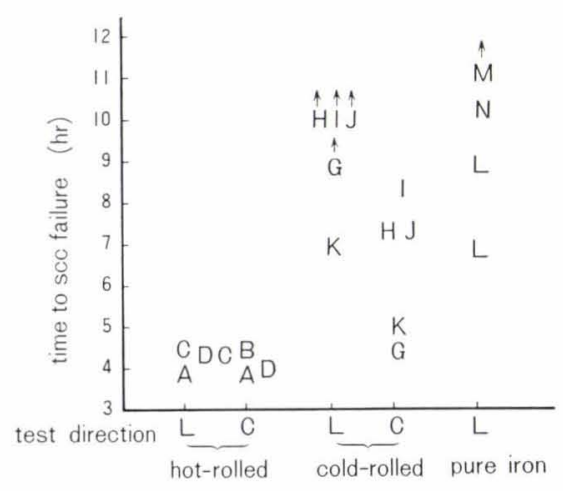

Fig. 3. SCC susceptibility of hot-rolled sheets, cold-rolled sheets, and pure iron sheets (short gauge-length specimen) of the SCC susceptibility among cold-rolled, pure iron and hot-rolled sheets. Tests were carried out using short gauge-length specimens immersed in a methanol solution of $0.01 \mathrm{wt} \%$ formic acid and $0.1 \mathrm{wt} \%$ water. Both longitudinal $(L)$ and transverse $(C)$ hot-rolled specimens of A, C and D were broken after 4 to $5 \mathrm{hr}$. The results indicated that differences in the materials, and between the $L$ and $C$ directions were not clearly ascertainable under this test condition.

Under this condition, the longitudinal specimens of cold-rolled sheets, specimen $\mathrm{K}$ (TS: $53.6 \mathrm{~kg} / \mathrm{mm}^{2}$ ), failed after about $7 \mathrm{hr}$. All the other specimens generated minor SCC in the bend, which did not lead to failure. The transverse specimens showed a higher SCC susceptibility, and they failed after a time shorter than that for longitudinal specimens. The failure was started by SCC in the bent. The times to failures of specimens $\mathrm{G}$ (TS: $33.2 \mathrm{~kg} / \mathrm{mm}^{2}$ ) and $\mathrm{K}$ (TS: $53.6 \mathrm{~kg} / \mathrm{mm}^{2}$ ) were shorter than that of specimens H, I and J, and were as short as that of hotrolled sheet specimens. However, no correlation was recognized between the time to failure and their chemical composition, tensile strength, etc.

The longitudinal specimens $\mathrm{L}$ and $\mathrm{N}$ of annealed cold-rolled pure iron sheets were broken starting from the SCG in the bend after about $8 \mathrm{hr}$ and $11 \mathrm{hr}$, respectively, showing an SCG susceptibility similar to that of longitudinal specimens of cold-rolled steel sheets. Though the specimen of pure iron sheet $\mathrm{M}$ generated a slight SCC in the bend, it did not break. This result indicates that its SCG susceptibility is lower than that of the specimens of other pure iron sheets $\mathrm{L}$ and $\mathrm{N}$.

A number of workers have studied the effect of carbon content on the susceptibility of mild steel to SCC in hot nitrate solution. These reports show that the susceptibility is the highest for steels containing about 0.05 to $0.10 \% \mathrm{C}$, which is the ordinary carbon range of commercial low-carbon steel sheets. Parkins, ${ }^{3)}$ for example, reported that the resistance to SCG increased with the carbon content in 0.07 to $0.22 \% \mathrm{C}$ steels, but that the $0.07 \% \mathrm{C}$ steel decarburized to $0.02 \% \mathrm{C}$ in wet hydrogen exhibited the negligibly small SCC susceptibility. Uhlig and Sava ${ }^{4}$ stated that a $0.06 \% \mathrm{C}$ steel and a $0.11 \% \mathrm{C}$ steel generated SCC in a short time, whereas a $0.001 \% \mathrm{C}$ iron was resistant. Flis $^{5)}$ also reported that there is a minimum time to failure for a certain content of carbon, lying between about 0.009 and $0.10 \% \mathrm{C}$ and a steel containing $0.000 \% \mathrm{C}$ reduced its SCC susceptibility. Their results indicate that the SCC in hot nitrate solution is quite sensitive to the carbon content with the highest SCC susceptibility at a certain carbon content. However, in methanol solution pure iron sheets with $0.001 \% \mathrm{C}$ and cold-rolled low-carbon steel sheets were corroded equally, indicating that the SCC susceptibility did not change at this level of carbon content.

\section{Effect of Chromium Content}

Chromium, one of the carbonitride formers, is known to be effective in reducing SCG in a nitrate solution. ${ }^{6,7)}$ Figure 4 shows the relations between 


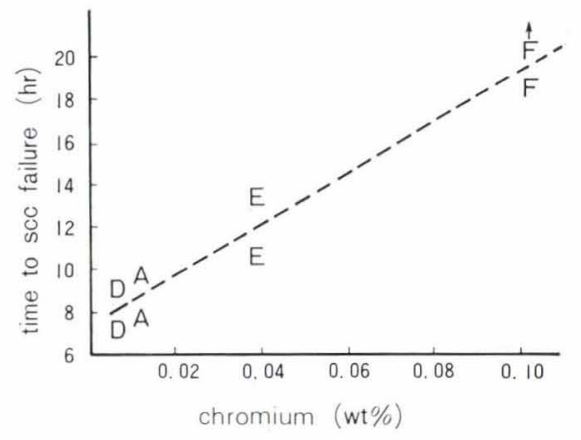

Fig. 4. Effect of $\mathrm{Cr}$ content on the time to SCC failure (long gauge-length specimen)

0.01 to $0.1 \%$ chromium contents of hot-rolled steel sheets $\mathrm{A}$ to $\mathrm{F}$ and their times to failure (long gaugelength specimens). This figure clearly shows that as the chromium content in a low-carbon steel sheet increases, the time to failure lengthens. The figure also shows that when the chromium content is above $0.04 \%$, their SCC susceptibility in methanol solution is sufficiently decreased.

Since copper is an anti-corrosive element in steel in various environments, it would be favorable in reducing SCC.

\section{Effect of Temper Rolling Reduction}

It is known that the SCC susceptibility depends on the deformation by rolling and the tensile stress in mild steel, ${ }^{3,4)}$ stainless steel ${ }^{8,9)}$ and brass. ${ }^{10)}$ Figure 5 shows the effects of temper rolling reduction up to $5 \%$ on their SCG susceptibility. Specimens A and D (short gauge-length) were temper rolled using a laboratory rolling mill. A $0.005 \%$ addition of formic acid enhanced the effect of temper rolling reduction, significantly shortening the time to failure, as the temper rolling reduction increased. With a $0.025 \%$ addition of formic acid, the effect of temper rolling reduction was not clearly seen because other corrosive factors were dominant. The effect of tensile prestrain up to $5 \%$ on SCG susceptibility was studied also and it was found that time to failure was not related to the amount of tensile prestrain. The strain by tensile deformation is uniformly distributed in the longitudinal and transverse sections of specimens along the direction of applied tension, whereas the strain by temper rolling is inhomogeneously, ${ }^{11)}$ distributed on the surface of a steel sheet. The rate of strain in the surface layer at the bend of specimens has, as will be discussed later in this report, a large effect on the generation of SCC. It may be considered that if an inhomogeneously strained area exists on the surface of a temper rolled sheet, the restretching of the bent part of the specimen increases the deformation in an undeformed, less hardened part by bending, and thus the strain rate of the bent part is optimized for generating SCC.

\section{Effect of Coiling Temperature}

Figure 6 shows the effect of coiling temperature of hot-rolled low-carbon rimmed steel sheets on SCC susceptibility. Three types of No. O steel sheets were commercially produced with the same conditions (chemical composition, finishing temperature, and

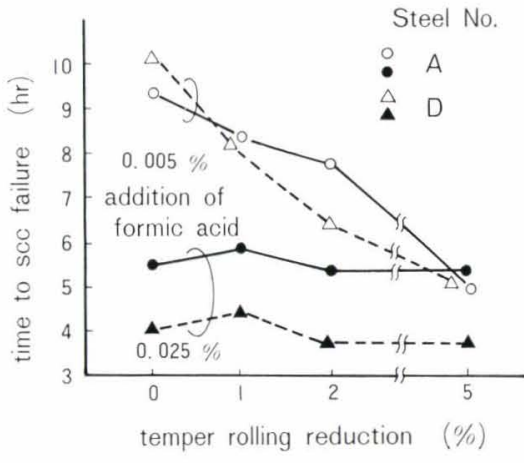

Fig. 5. Effect of temper rolling reduction on the time to SCC failure (short gauge-length specimen)

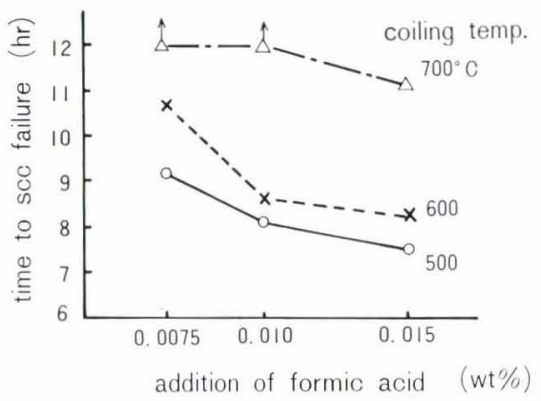

Fig. 6. Effect of hot strip coiling temperature $\left({ }^{\circ} \mathrm{C}\right)$ on the time to SCC failure (steel No. O short gauge-length specimen)

temper rolling reduction), but coiled at three different coiling temperatures, $500^{\circ}, 600^{\circ}$ and $700^{\circ} \mathrm{C}$. Under the test condition of a $0.0075 \%$ formic acid addition, a specimen of sheet, which was coiled at $700^{\circ} \mathrm{C}$, generated weak SCC in the bent part, but did not fail in $12 \mathrm{hr}$. On the contrary, the specimens coiled at $600^{\circ} \mathrm{C}$ failed after about $11 \mathrm{hr}$ and those coiled at $500^{\circ} \mathrm{C}$ broke after about $9 \mathrm{hr}$. Under the severer SCC test conditions of $0.01 \%$ and $0.015 \%$ formic acid additions, time to failure increased with the coiling temperature. Thus, the high coiling temperature is effective in decreasing the SCC susceptibility of sheets.

The type of carbide formed in the steel sheet coiled at $700^{\circ} \mathrm{C}$ was cementite and that coiled at $500^{\circ} \mathrm{C}$ was pearlite (Photo. 1). Coiling temperature in a range of $500^{\circ}$ to $700^{\circ} \mathrm{C}$ affects both the carbide type in hotrolled low-carbon steel sheets ${ }^{12)}$ and the precipitation of aluminum nitride $(\mathrm{AlN})^{13}$ in hot-rolled alminumkilled steel sheets. Since SCG is not generated in a pure iron sheet in hot nitrate solution, which is considered promotive of SCC in mild steel, carbon and nitrogen are considered to influence the SCG susceptibility of the steel. The change of the susceptibility by heat-treating conditions suggests that the SCC susceptibility is related not only to the amounts of carbon and nitrogen contents, but also the accumulation form of carbon and nitrogen at the grain boundary where failure would occur. ${ }^{4}$ ) Therefore, the change of the SCG susceptibility of hot-rolled steel sheets by coiling temperature can be explained in terms of the change of accumulation form of carbon and nitogen atoms at the grain boundary.

\section{Effect of Heat Treatment}

The SCC susceptibility of water-quenched low- 


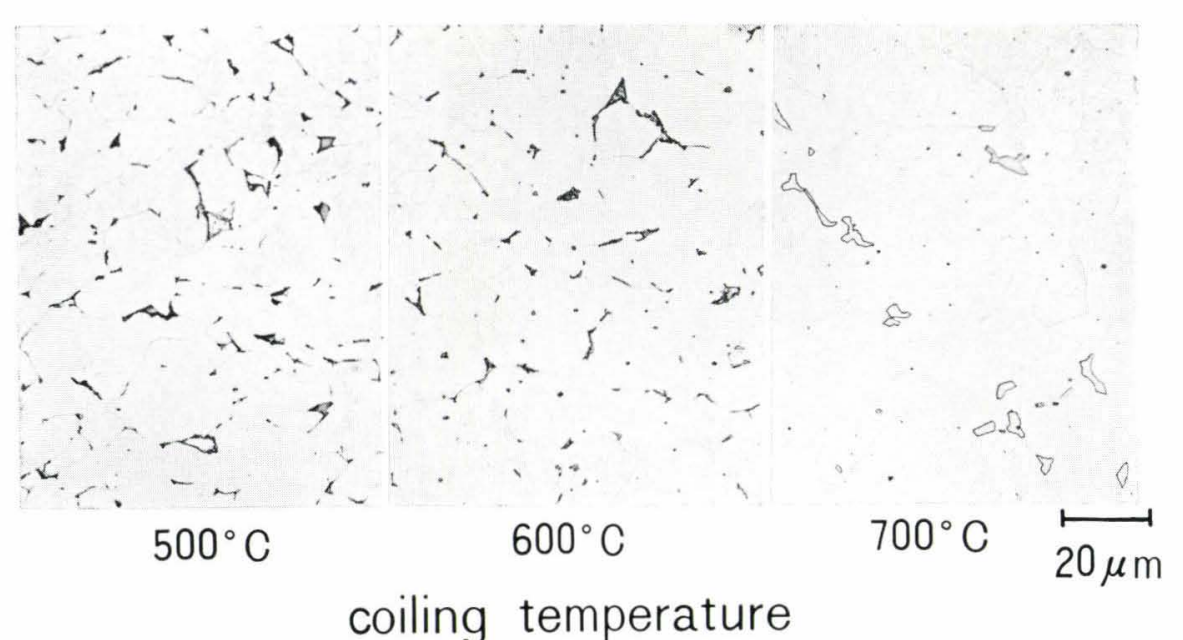

Photo. 1. Influence of hot strip coiling temperature on carbide type and distribution (steel No. O)

Photo. 2.

Influence of heat treatment temperature for $5 \mathrm{hr}$ on carbide type and distribution of as rolled specimen (steel No. O, coiling temp.: $500^{\circ} \mathrm{C}$ )

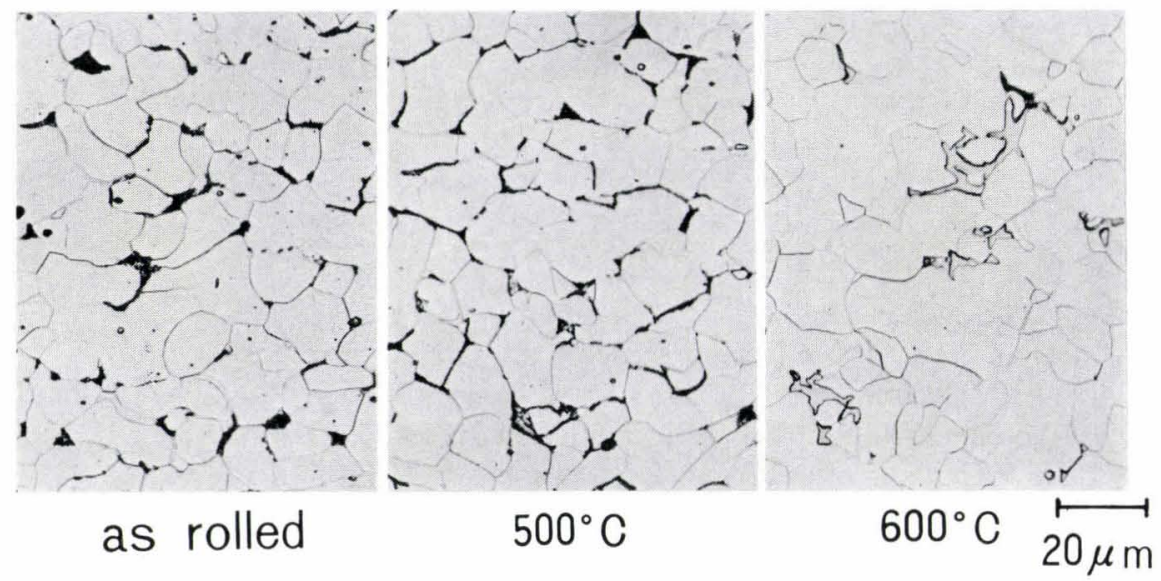

morphological changes of carbides in the steel sheets coiled at $500^{\circ} \mathrm{C}$ and subsequently heat-treated at $500^{\circ}$ and $600^{\circ} \mathrm{C}$ for $5 \mathrm{hr}$. The carbide produced by heat-treatment of $500^{\circ} \mathrm{C} \times 5 \mathrm{hr}$ or lower was pearlitic, the same as that of as-rolled sheets, but the heat treatment at $600^{\circ} \mathrm{C} \times 5 \mathrm{hr}$ turned a part of pearlite into massive cementite. The SCC susceptibility, however, was high in a heat-treating temperature range of $100^{\circ}$ to $300^{\circ} \mathrm{C}$ and became low at $500^{\circ} \mathrm{C}$ or higher, as shown in Fig. 7, indicating that the change in SCG susceptibility did not correspond to the morphological change of the microscopic carbide. The observation of carbide by means of an electron microscope of a high magnifying power $(\sim \times 10000)$ showed only the morphological change of carbide by the heattreatment at $600^{\circ} \mathrm{C} \times 5 \mathrm{hr}$. The change in SCC susceptibility could not be correlated to either the change in the amount of solid solution $(\mathrm{C}+\mathrm{N})$ obtained by measuring internal friction or the changes in mechanical properties such as YP, TS, El and HRB. Therefore, the present test could not clarify the relation between the change in SCC susceptibility by coiling temperature or heat-treatment and the change in the carbide morphology. Since the SCC susceptibility significantly changed in a relatively low temperature range of $100^{\circ}$ to $300^{\circ} \mathrm{C}$, the change of the $\mathrm{SCC}$ susceptibility could be related to the change in the state of super-microscopic carbon and nitrogen, e.g., 
atomic carbon and nitrogen ${ }^{4)}$ in the grain boundary. 7. Effect of the Cooling-rate from the Austenite $(\gamma)$ Region

The SCC susceptibility of mild steel in nitrate solution is affected by the cooling-rate from the $\gamma$ region. ${ }^{4,7,14)}$ The specimens (steel No. P) were oilquenched, water-shower cooled or air-cooled after heating at $950^{\circ} \mathrm{C}$ for $15 \mathrm{~min}$ in an argon atmosphere. Average cooling rates from $950^{\circ}$ to $500^{\circ} \mathrm{C}$ were $\sim 150^{\circ}, \sim 40^{\circ}$, and $\sim 10^{\circ} \mathrm{C} / \mathrm{sec}$, respectively. These heat-treatments simulate the actual strip cooling-rate between the finishing roller and the coiler in the hot rolling process. Then, some of the specimens were vacuum heat-treated in a temperature range of $200^{\circ}$ to $700^{\circ} \mathrm{C}$ for $5 \mathrm{hr}$ to investigate the effects of coolingrate and heat-treatment on the SCG susceptibility of the specimens. The test results of as-cooled specimens are shown in Fig. 8. The oil-quenched specimen, which had been subjected to the fastest coolingrate, failed by SCC after about $4 \mathrm{hr}$, indicating a high SCC susceptibility. Both the water-shower cooled specimen and the air-cooled specimens, however, generated only a weak SCG and did not fail in $10 \mathrm{hr}$. The crack on the water-shower cooled specimen was large enough to visibly ascertain, whereas that on the air-cooled specimen was so small that only a microscope of a low magnifying power could ascertain it. Accordingly, the SCG susceptibility of the oil-quenched specimen was the highest, that of the watershower cooled specimen was next, and then that of the air-cooled specimen was the lowest. This means that the high cooling-rate from the $\gamma$ region increases the SCG susceptibility. Hence, it can be assumed that one of the reasons for the high SCC susceptibility of the hot-rolled sheets with a low coiling temperature has a higher strip cooling-rate between the finishing roller and the coiler.

Time to failure of the oil-quenched specimen increased linearly by heat-treatment from $200^{\circ}$ to $700^{\circ} \mathrm{C}$ for $5 \mathrm{hr}$, and the specimen heat-treated at $700^{\circ} \mathrm{C}$ did not fail by SCC in $10 \mathrm{hr}$.

\section{Cracking Mechanism of Bent Specimen}

\section{Progress of Cracking}

The specimens failed after 5 to $20 \mathrm{hr}$ under an adequate test condition in the constant strain-rate test of bent specimens. The failure always started from SCC generated on the inner surface of the bent part. In order to investigate the progress of SCG in the specimen, this constant strain-rate test was stopped in the middle of the test. Figure 9 shows time-load relations of the constant strain-rate test. Steel sheet $O$ (coiling temperature: $500^{\circ} \mathrm{C}$ ) was used for the specimens and short gauge-length specimens were immersed in a methanol solution $\left(60^{\circ} \mathrm{C}\right)$ of $0.01 \%$ formic acid and $0.1 \%$ water.

Photograph 3 shows the time dependent change in the shape of a bent specimen. As tension was applied to the specimen, the $\mathrm{B}$ section ( $10 \mathrm{~mm}$ radius), the center of the specimen, first began to stretch and became virtually flat after about $2 \mathrm{hr}$. The increase of load during this period of time was gradual. As ten-

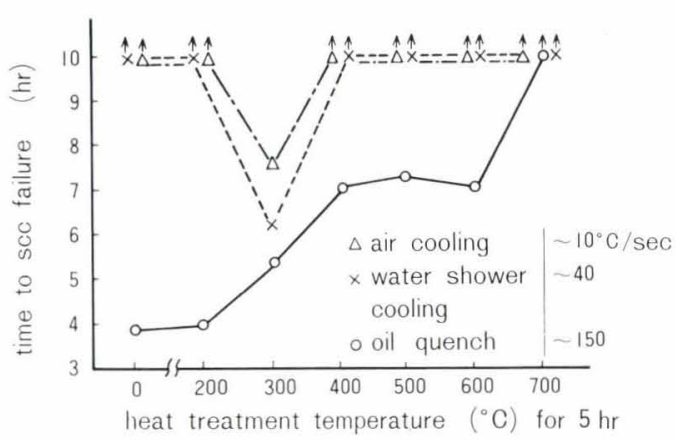

Fig. 8. Effect of cooling rate and heat treatment temperature for $5 \mathrm{hr}$ on the time to SCC failure (steel No. $\mathrm{P}$, short gauge-length specimen)

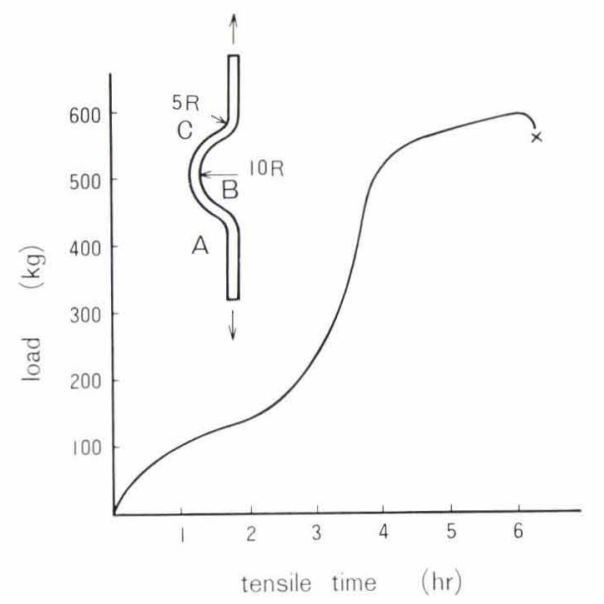

Fig. 9. Relation between tensile time and load of bent short gauge-length specimen (crosshead speed: $0.05 \mathrm{~mm}$ / $\min$ )

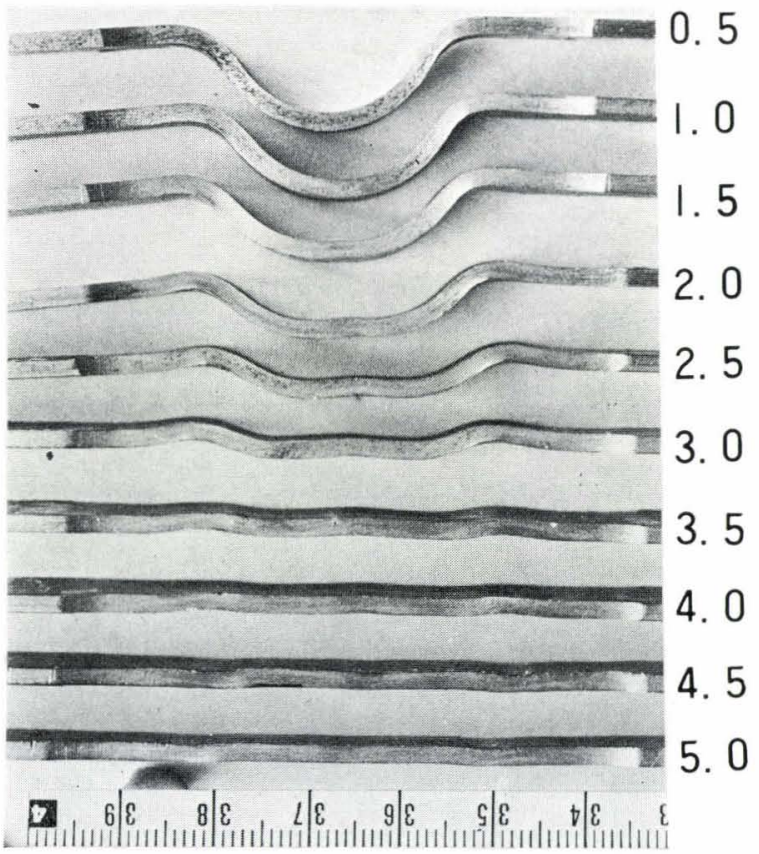

Photo. 3. Relation between tensile time (hr) and shape of bent specimen (crosshead speed: $0.05 \mathrm{~mm} / \mathrm{min}$ )

sion was further applied, the A and $\mathrm{C}$ sections $(5 \mathrm{~mm}$ radius) started to stretch simultaneously and became almost flat after about another $2 \mathrm{hr}$. The load dur- 


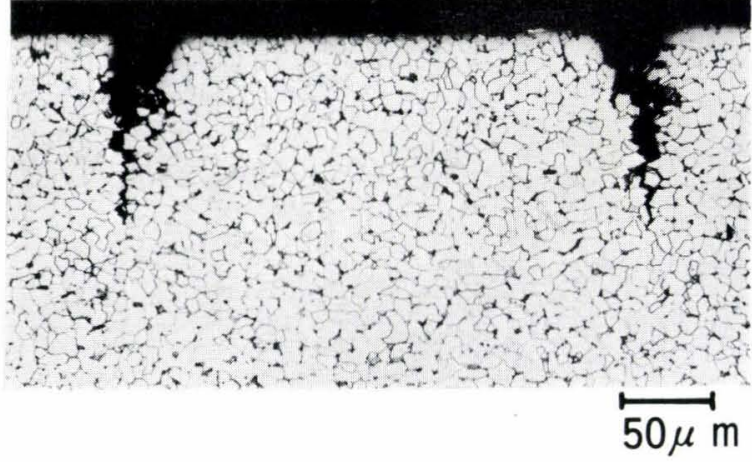

Photo. 4. Stress corrosion cracking observed on bent specimen after constant strain rate test $(2.5 \mathrm{hr})$

ing this period of time increased rapidly and passed the yield point after about $4 \mathrm{hr}$, becoming practically flat. The specimen failed after $6 \mathrm{hr}$. Photograph 4 shows SCG generation in the A section after $2.5 \mathrm{hr}$ from the start of tensioning.

Figure 10 shows the depths of SCG in A, B and C sections, measured every $30 \mathrm{~min}$. Although no crack was observed $30 \mathrm{~min}$ after the start of tensioning, they initiated after one hour in the B section, which first began to stretch. Cracks progressed till the depth reached to $0.15 \mathrm{~mm}$ in $2 \mathrm{hr}$. Propagating speed was approximately $0.1 \mathrm{~mm} / \mathrm{hr}$ at this period of time. After $2 \mathrm{hr}$, progress of cracking stopped. This time coincided with the period of flattening of the B section, as shown in Photo 3. It can be assumed, therefore, that because of no further stretching of the B section the progress of cracking stopped. Cracking in the $\mathrm{A}$ and $\mathrm{C}$ sections started 2 hr later than cracking in the $\mathrm{B}$ section and progressed to a depth of $0.22 \mathrm{~mm}$ in $4 \mathrm{hr}$. The time of crack starting and that of temporary stop of cracking in the A and C sections generally coincided, as in the case of $\mathrm{B}$ section, with the time of the start of stretching and the time of the end of stretching, respectively, in the sections. Therefore it was concluded that cracking progressed only during stretching of the bent part of the specimen. When the entire specimen became flat $30 \mathrm{~min}$ before its failure, deformation concentrated in the A, $\mathrm{C}$ and $\mathrm{B}$ sections, where cracking had already occurred. Then, cracking, halted once, began to propagate again, and finally, the specimen failed by ductile fracture when the tensile load became greater than the strength of the remaining thickness of the specimen.

\section{Effect of Bent Depth of Specimen}

Both Fig. 10 and Photo. 3 show that SCG progressed while the bent parts of the specimens were being stretched. The observed results indicate that the crack would be deeper if the bent depth $(10 \mathrm{~mm})$ in Fig. 1 is greater and the time required to flatten the bent parts is prolonged.

The results of the test conducted on steel sheet $B$ using short gauge-length specimens with varying bent depth are shown in Table 2, where it is clear that the crack depth in the $\mathrm{B}$ section increases with increasing the bent depth. This is attributed to the fact that the flattening time, namely, time during which crack-

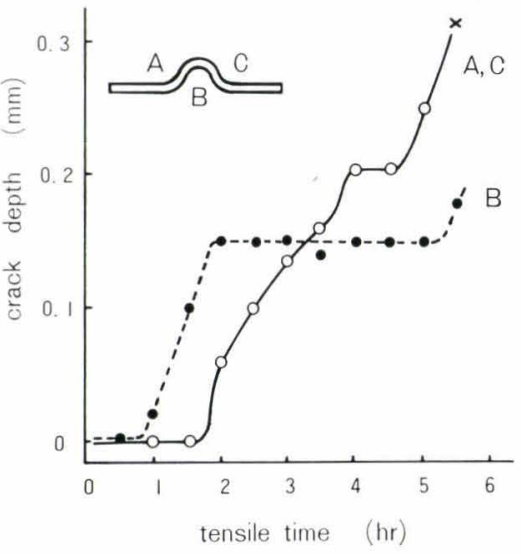

Fig. 10. Effect of tensile time on crack depth (steel No. O, short gauge-length specimen)

Table 2. Effect of bent depth on crack depth (steel No. B short gauge-length specimen)

\begin{tabular}{c|cccc} 
bent depth $h(\mathrm{~mm})$ & 8 & 10 & 13 \\
time to failure (hr) & $5^{\circ} 30^{\prime}$ & $6^{\circ} 15^{\prime}$ & $7^{\circ} 33^{\prime}$ \\
\begin{tabular}{c|ccc} 
crack depth \\
(mm)
\end{tabular} & B & 0.20 & 0.23 & 0.28 \\
& A, C & 0.20 & 0.20 & 0.20
\end{tabular}

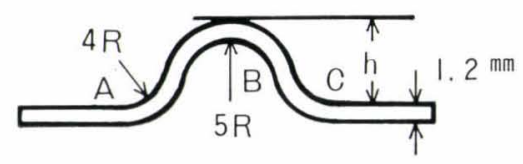

ing progressed was prolonged. On the other hand, the crack depth in the $\mathrm{A}$ and $\mathrm{C}$ sections did not change with the change of bent depth, because the time required to flatten these bent sections was not affected by the bent depth. Time to failure was the longest for the specimen with a bent depth of $13 \mathrm{~mm}$ and, as a result, the deepest crack was generated. This is because the deeper the bend is, the longer the time to flatten is, and this prolonged time is included in the total time to failure.

\section{Effect of Radius of Curvature}

The bend of a specimen played an important role in the generation of SCC. Compressive strain, however, was produced on the inner surface of the bend of the specimens. In order to investigate the effect of this compressive strain on SCG depth, a test was carried out with the specimens (steel No. B) having a radius of a curvature in a range of 4 to $10 \mathrm{~mm}$ at the $\mathrm{A}$ and $\mathrm{C}$ sections. The crack depth, as stated in the former section, would increase in proportion to a prolonged time to flatten the bend, and the change in the radius of curvature at the $\mathrm{A}$ and $\mathrm{C}$ sections could cause a corresponding change in the time to flatten these sections. However, the observation of tensile time-load relations of specimens having a radius of curvature in a range of 4 to $10 \mathrm{~mm}$ revealed that time to flatten A and C sections hardly changed but remained around $2 \mathrm{hr}$. It was shown, therefore, that change within the range of $4 \sim 10 \mathrm{~mm}$ in the radius of curvature would not affect the time to flatten these 


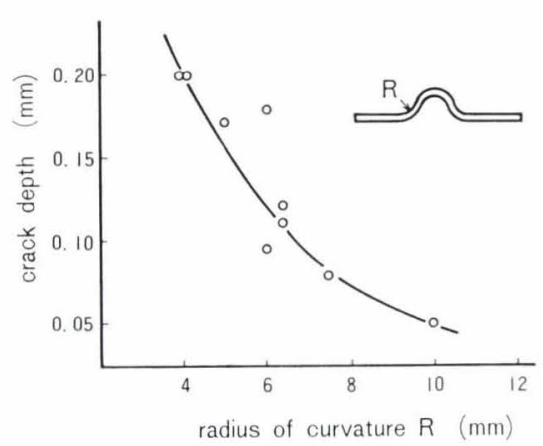

Fig. 11. Effect of radius of curvature of bent short gaugelength specimen on crack depth (steel No. B)

sections. Figure 11 shows the relations between the radius of curvature of the $\mathrm{C}$ section and the crack depth which was reached in $4 \mathrm{hr}$ after the start of tensioning. Then the flattening and cracking of the specimen was temporarily stopped in the $\mathrm{A}$ and $\mathrm{C}$ sections. Figure 11 indicates the smaller the radius of curvature, the greater the compressive strain on the surface of specimen by bending, and the deeper the crack.

Figure 12 shows the relations between the crack depth and the compressive strain on the surface of the specimen calculated on the basis of a simple bending theory, assuming that the neutral plane in the middle of the thickness of the sheet $(\varepsilon=\eta / \rho, \varepsilon$ : strain, $\eta$ : distance from the neutral plane, mm, $\rho$ : radius of curvature, $\mathrm{mm}$ ) is undeformed. Because these relations are linear, the strain value at which the crack depth is zero, i.e., no SCG generates, could be calculated by extrapolating the line in Fig. 12, and obtained the strain of $\varepsilon \fallingdotseq 0.03$ (radius of curvature: $20 \mathrm{~mm}$ ).

In this test method, the SCG depth increased in proportion to the increase in the compressive strain $\varepsilon$ on the inner surface of the bend of a specimen within a compressive strain range of $0.03 \sim 0.15$. In the constant strain-rate test, the rate of strain has a large effect on SCG susceptibility of a specimen. ${ }^{16}$ ) Namely, if the strain-rate is excessive, the specimen will fail by ductile fracture before corrosion reaction progresses. If the strain-rate is insignificant, the protective film will recover the specimen surface damaged by plastic deformation before an SCC promoting corrosive substance reaches the bare surface of the specimen. The high and low strain rates mentioned above do not cause SCC, but SCC is generated in medium strain rates. The SCC promotive strain-rate $\dot{\varepsilon}$ is, according to an exposition given by Parkins et al. ${ }^{16)} \dot{\varepsilon} \sim$ $10^{-6} \mathrm{sec}^{-1}$ for mild steel in boiling nitrate solution. In an $\mathrm{H}_{2} \mathrm{~S}$ saturated aqueous solution, the SCC (but by hydrogen embrittlement) susceptibility is highest in the strain-rate region of $10^{-4}$ to $10^{-5} \mathrm{sec}^{-1}$, according to Kawashima et al. ${ }^{17)}$

Accordingly, the effect of the radius of curvature on the SCC susceptibility of a bent specimen can be explained as the difference in the strain rate caused by the difference in compressive strain $\varepsilon$. That is, the time required to flatten the $\mathrm{A}$ and $\mathrm{C}$ sections was constant and had no relation to the radius of their cur-

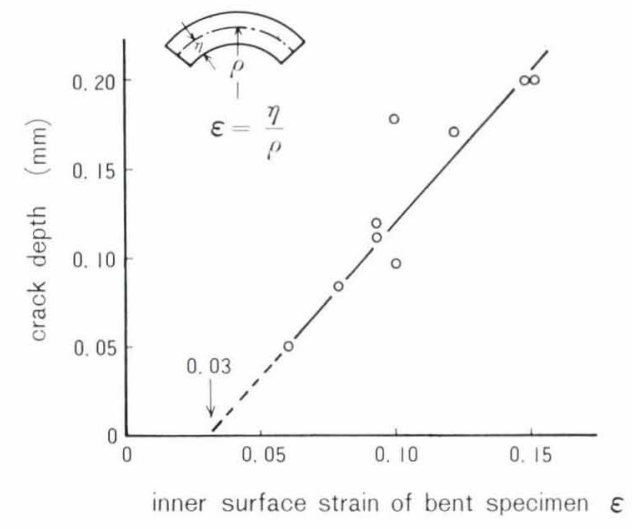

Fig. 12. Relation between inner surface strain of bent specimen and crack depth (steel No. B, 1.2 mm thick)

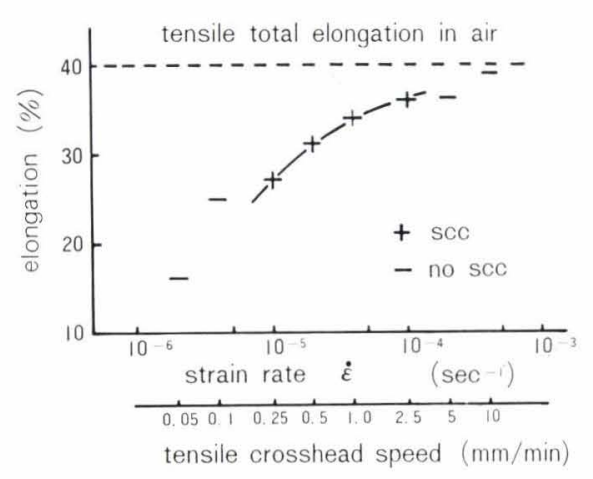

Fig. 13. Effect of strain rate $\dot{\varepsilon}$ on tensile total elongation (steel No. C, long gauge-length specimen)

vature $(4 \sim 10 \mathrm{~mm})$, and hence the strain-rate (strain/ time) is determined primarily by the compressive strain $\varepsilon$. In the case of $\varepsilon=0.03$ (radius of curvature: $20 \mathrm{~mm}$ ) which was posited previously, if this compressive strain is assumed to become zero by tension in $2 \mathrm{hr}$, then the average strain-rate on the inner surface of the bent sections is $\dot{\varepsilon}=4.2 \times 10^{-6} \mathrm{sec}^{-1}$, and this value was too small to generate SCC. On the other hand, the average strain-rate in the case of $\varepsilon=$ 0.15 (radius of curvature: $4 \mathrm{~mm}$ ) will likewise be $\dot{\varepsilon}=$ $2.1 \times 10^{-5} \mathrm{sec}^{-1}$, and this value is considered favorable to the generation of SCC.

\section{Effect of Tensile Strain-rate with Straight Specimens}

Attempts were made to clarify the effect of the strain-rate discussed in the former section on SCC susceptibility using straight specimens. Figure 13 shows the change in the total elongation (gauge length: $50 \mathrm{~mm}$ ) with the strain-rate $\dot{\varepsilon}$ on a straight long gauge-length specimen (steel No. C) in a range of $2 \times 10^{-6}$ to $4 \times 10^{-4} \mathrm{sec}^{-1}$ (tensile crosshead speed: $0.05 \sim 10 \mathrm{~mm} / \mathrm{min})$. The total elongation at the largest strain-rate of $4 \times 10^{-4} \mathrm{sec}^{-1}$ was $40 \%$ which is as large as the total elongation in the air, and no SCC generation was observed on it. In a strain rate range of $10^{-4}$ to $10^{-5} \mathrm{sec}^{-1}$, SCC was generated on both surfaces of the specimen, and the total elongation was reduced in proportion to the decrease in strain-rate. Below the strain rate of $4 \times 10^{-6} \mathrm{sec}^{-1}$ the total elongation was further reduced to a minimum of $16 \%$. In this case, although no SCC was observed in 
a uniformly elongated section of the specimen, SCC was found in the necking part of the specimen because the strain-rate in this part was several tens times larger than the average strain-rate of the entire specimen as the elongative deformation was converged in the part where necking at first started.

It was, therefore, ascertained that SCC was generated in a straight specimen in methanol solution, and that the strain-rate had a large effect on SCG generation. The range of the strain-rate where SCC was generated under the present test condition was $1 \times 10^{-5}$ to $1 \times 10^{-4} \mathrm{sec}^{-1}$. This was nearly equivalent to the value obtained by the test with bent specimens described in the former section. It was also ascertained that the minimum SCG generating strain-rate depended on the material of specimen. Steel sheet C, for example, did not generate SCG at a strain-rate below $4 \times 10^{-6} \mathrm{sec}^{-1}$, whereas steel sheet $\mathrm{D}$, which showed a stronger SCC susceptibility than steel sheet $\mathrm{C}$, generated $\mathrm{SCG}$ even at a strain-rate of $2 \times 10^{-6}$ $\sec ^{-1}$.

In the previous report ${ }^{11}$ it was described that no SCG was generated in straight specimens (gauge length: $400 \mathrm{~mm}$; tensile crosshead speed: $0.05 \mathrm{~mm} /$ $\mathrm{min})$. This was because the strain-rate of $2 \times 10^{-6}$ $\mathrm{sec}^{-1}$ was too small to generate SCC. On the other hand, the bent specimens tested by the same condition as the straight specimens generated SGC because the strain-rate became large enough to promote SCG as tensile deformation concentrated in the bent sections in the process of tensioning.

The maximum depth of SCG found in straight specimens was $0.05 \mathrm{~mm}\left(\dot{\varepsilon}=10^{-4} \mathrm{sec}^{-1}\right)$ and was considerably smaller than that found in bent specimens (max. $0.28 \mathrm{~mm}$ ). The experimental result indicates that the bent specimens are more suitable than the straight specimens for the comparison of SCG susceptibility between various types of steel sheets or between different test environments.

Figure 14 shows the effect of strain-rate on the SCC susceptibility of short gauge-length straight specimens. $\mathrm{SCC}$ occurred in these specimens in the strain-rate range of $1.4 \times 10^{-5}$ to $2.0 \times 10^{-4} \mathrm{sec}^{-1}$, which generally agreed with the range for long gauge-length specimens in Fig. 13.

$O$ and $\Delta$ in Fig. 14 represent the total elongation values of the same specimen tested in turbine oil at $20^{\circ}$ and $60^{\circ} \mathrm{C}$, respectively. In turbine oil at $20^{\circ} \mathrm{C}$

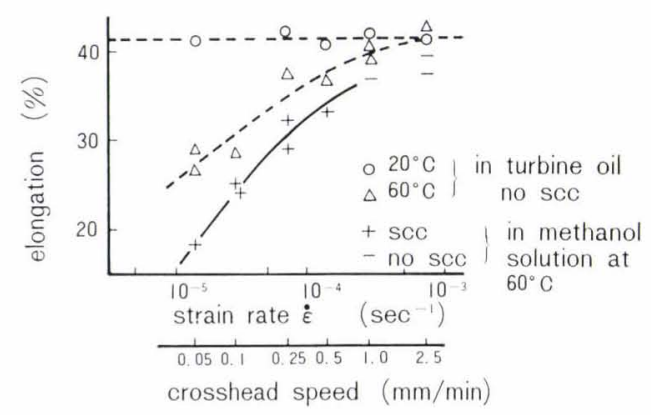

Fig. 14. Effect of strain rate $\dot{\varepsilon}$ on tensile total elongation (steel No. O, short gauge-length specimen) the total elongation was little affected by the tensile crosshead speed and showed the same value as in air. On the contrary, the total elongation was reduced proportionately with the decrease in the strain-rate at $60^{\circ} \mathrm{C}$. At the minimum strain-rate the total elongation was about $14 \%$ less than that at $20^{\circ} \mathrm{C}, 41 \%$. The failure of the specimen in the turbine oil was characterized as a ductile fracture and no SCC was observed.

Thus, the total elongation of hot-rolled low-carbon steel sheet, most of which is failed by ductile fracture, will be significantly reduced in a tensile test of a sufficiently small strain-rate at $60^{\circ} \mathrm{C}$ by dynamic strain aging.

The reduced total elongation of a straight specimen at a small strain-rate in methanol solution at $60^{\circ} \mathrm{C}$ is ascribable not only to the SCG generation but also to the decrease in the ductility of the specimen.

\section{SCC in Organic Solvents Other than Methanol \\ 1. Ethanol}

Constant strain-rate test (tensile crosshead speed: $0.05 \mathrm{~mm} / \mathrm{min}$ ) of short gauge-length bent specimens (steel No. O) was carried out in pure grade reagent ethanol solution of formic acid or acetic acid and water additions. The test temperature was kept at $60^{\circ} \pm 0.1^{\circ} \mathrm{C}$. In an ethanol solution of 0.01 to $0.25 \%$ formic acid and $0.1 \%$ water additions, no SCC was observed even after about $10 \mathrm{hr}$ of tensioning. But SCC was observed on the inner surface of the bent parts of specimens tested in an ethanol solution of $0.01 \%$ acetic acid and $0.1 \%$ water additions. This SCC was very slight, however, as compared to that generated in methanol solution, and the depth of crack was less than $0.01 \mathrm{~mm}$. There was a possibility of generating severer SCG by selecting a suitable strain-rate and suitable percentage of acetic acid and water additions. Because acetic acid, which is produced through acetoaldehyde $\left(\mathrm{CH}_{3} \mathrm{CHO}\right)$ by oxidation of ethanol, is weaker than formic acid, the severe SCC generated in methanol solution will not be generated in ethanol solution.

\section{Methyl Gellosolve}

Methyl cellosolve (ethylene glycol monomethyl ether, 2-methoxy-ethanol), one of the polyalcohols, is a colorless transparent liquid at room temperature, having a rational formula of $\mathrm{H}_{3} \mathrm{COC}_{2} \mathrm{H}_{4} \mathrm{OH}$, a molecular weight of 76.09 and a boiling point of $124.4^{\circ} \mathrm{C}$, and is used as a solvent of nitrocellulose and acetylcellulose groups. ${ }^{18)}$

The same test, as described in the former section, was conducted in a pure grade reagent methyl cellosolve solution of formic acid or acetic acid and water addition at $80^{\circ} \pm 0.1^{\circ} \mathrm{C}$. At formic acid additions of $0,0.005$ and $0.05 \%$, the generation of SCC was not observed, but SCC occurred at 0.01 and $0.02 \%$. This SCC also occurred on the inner surface of the bent parts of the specimens and was characterized by the cracking in the grain boundary. The $\mathrm{SCC}$, however, was not so severe (max. crack depth: $0.15 \mathrm{~mm}$ ) as to cause the specimen to fail from this 
SCC. At a formic acid addition of $0.01 \%$, SCC was observed in a methanol solution of water in a range of 0 to $2 \%$ addition, but was not when water addition exceeded $5 \%$. In the case of a methanol solution with additional $0.01 \%$ formic acid, $0.01 \%$ water accelerated SCC, but $0.5 \%$ or more inhibited SCC. ${ }^{1)}$ The similar water effect can be expected for the methyl cellosolve solution. SCG was observed in a specimen in methyl cellosolve solution of 0.02 to $0.1 \%$ acetic acid and $0.1 \%$ water, but was considerably milder than that generated in methyl cellosolve solution of formic acid.

\section{Ethylene Glycol}

Ethylene glycol, also one of the polyalcohols, takes the form of a somewhat sticky, colorless, transparent liquid at room temperature, and has a rational formula of $\mathrm{C}_{2} \mathrm{H}_{4}(\mathrm{OH})_{2}$, a molecular weight of 62.07 , and a boiling point of $197.9^{\circ} \mathrm{C}$. It is used mainly as an anti-freezing solution, working fluid, ${ }^{18)}$ etc.

A similar test was carried out in an ethylene glycol solution of formic acid or acetic acid and water addition at $80^{\circ} \pm 0.1^{\circ} \mathrm{C}$. In an ethylene glycol solution of 0.01 to $0.05 \%$ formic acid and $0.1 \%$ water addition, SCC occurred on the inner surface of the bent parts of the specimens. The crack was slight and showed the maximum depth of $0.05 \mathrm{~mm}$. In an ethylene glycol solution of $0.1 \%$ water and 0.01 to $0.05 \%$ acetic acid addition, no SCC was noticed.

\section{Conclusion}

The effect of the properties of mild steel on the SCG susceptibility in methanol solution of minute amounts of formic acid and water additions was investigated using the constant strain-rate test method. The SCG susceptibility of cold-rolled and hot-rolled steel sheets did not relate to their tensile strength (TS: $23 \sim 60 \mathrm{~kg} / \mathrm{mm}^{2}$ ) or carbon content (0.001 $0.12 \%)$. SCG also occurred in pure iron sheets, but the SCC susceptibility of hot-rolled steel sheets containing $0.04 \%$ or more chromium was found to be low. It was ascertained that the SCG susceptibility decreased with decreasing the temper rolling reduction $(0 \sim 5 \%)$, and with increasing the coiling temperature. Heat treatment of hot-rolled steel sheets in a range of $100^{\circ} \sim 300^{\circ} \mathrm{C}$ for $5 \mathrm{hr}$ increased the $\mathrm{SCC}$ susceptibility, and heat treatment at $400^{\circ} \mathrm{C}$ for $5 \mathrm{hr}$ decreased it. Also a high cooling rate $\left(\sim 150^{\circ} \mathrm{C}\right.$ $\mathrm{sec}^{-1}$ ) from the austenite region increased the SCC susceptibility.

SCG generation on the inner surface of the bent part of the specimens in methanol solution was investigated using bent specimens with various bent depths and different radii of curvatures and the effect of the bend on SCC generation was analyzed. When a bent specimen was tensioned at a tensile rate of
$0.05 \mathrm{~mm} / \mathrm{min}$, the inner surface of the bent part of the specimen was deformed at a strain-rate suitable for generating SCC. This was considered to be the reason for the occurrence of SCC on the bent part of the specimen. In order to confirm the veracity of this reasoning, a straight specimen was tensioned at a strain-rate in the range of $10^{-3}$ to $10^{-6} \mathrm{sec}^{-1}$. The specimen generated SCC on both surfaces at a strainrate in the range of $10^{-4}$ to $10^{-5} \mathrm{sec}^{-1}$. Namely, the SCC susceptibility is the highest in the strain-rate range of $10^{-4}$ to $10^{-5} \mathrm{sec}^{-1}$ in methanol solution. The depth of the crack generated in the straight specimen, however, was smaller than that in the bent specimen. SCG occurred in low-carbon steel sheet in ethanol, methyl cellosolve and ethylene glycol solution containing a minute amount of formic acid or acetic acid and water as in methanol solution.

\section{Acknowledgements}

The authors express their appreciation to Mr. Y. Kokabu of the Technical R \& D Office of Sakai Works, now at Fundamental Research Laboratories, NSC, for his cooperation in those tests.

\section{REFERENCES}

1) K. Matsukura, K. Sato and Y. Kokabu: Tetsu-to-Hagané, 62 (1976), 1025.

2) S. Fujii: Kinzoku Bōshoku Gijutsu Binran (Handbook of Corrosion Engineering), ed. by Japan Society for the Promotion of Science, Nikkan Kogyo Shinbunsha, (1972), 663.

3) R. N. Parkins: JISI, 172 (1952), No. 2, 149.

4) H. H. Uhlig and J. Sava: Trans. ASM, 56 (1963), 361.

5) J. Flis: Corrosion-NACE, 29 (1973), No. 1, 37.

6) R. N. Parkins and A. Brown: JISI, 193 (1959), No. 1, 45.

7) H. Uhlig, K. E. Perumal and M. Talerman: CorrosionNACE, 30 (1974), No. 7, 229.

8) T. Maekawa, M. Kagawa and N. Nakajima: J. Japan Inst. Metals, 27 (1963), 548.

9) M. Watanabe, Y. Mukai and A. Sone: J. Japan Welding Society, 36 (1967), 1015.

10) S. Hori and T. Takemoto: J. Japan Inst. Metals, 37 (1973), 257.

11) R. D. Butler and D. V. Wilson: JISI, 201 (1963), No. 1, 16.

12) P. N. Richards and K. V. Barratt: Trans. ASM, 58 (1965), 601.

13) H. F. Beeghly: Anal. Chem., 21 (1949), 1513.

14) R. N. Parkins, P. W. Slattery, W. R. Middleton and M. J. Humphries: Brit. Corros. J., 8 (1973), No. 5, 117.

15) M. Kowaka and M. Kitamura: J. Japan Inst. Metals, 39 (1975), 381.

16) R. N. Parkins, F. Mazza, J. J. Royuela and J. C. Scully: Brit. Corros. J., 7 (1972), No. 7, 154.

17) A. Kawashima, M. Takano, K. Hashimoto and S. Shimodaira: J. Japan Inst. Metals, 38 (1974), 247.

18) Yōzai Pocket Book (Pocket Book of Solvents), ed. by The Society of Synthetic Organic Chemistry, Japan, The OHM Sha, Ltd., (1967). 